\title{
Supporting parents of preschool children in adopting a healthy lifestyle
}

Lucie Lemelin $^{1^{*}}$, Frances Gallagher ${ }^{2 \dagger}$ and Jeannie Haggerty ${ }^{3+}$

\begin{abstract}
Background: Childhood obesity is a public health epidemic. In Canada 21.5\% of children aged 2-5 are overweight, with psychological and physical consequences for the child and economic consequences for society. Parents often do not view their children as overweight. One way to prevent overweight is to adopt a healthy lifestyle (HL). Nurses with direct access to young families could assess overweight and support parents in adopting HL. But what is the best way to support them if they do not view their child as overweight? A better understanding of parents' representation of children's overweight might guide the development of solutions tailored to their needs.

Methods/design: This study uses an action research design, a participatory approach mobilizing all stakeholders around a problem to be solved. The general objective is to identify, with nurses working with families, ways to promote HL among parents of preschoolers. Specific objectives are to: 1) describe the prevalence of overweight in preschoolers at vaccination time; 2) describe the representation of overweight and $\mathrm{HL}$, as reported by preschoolers' parents; 3 ) explore the views of nurses working with young families regarding possible solutions that could become a clinical tool to promote $\mathrm{HL}$; and 4) try to identify a direction concerning the proposed strategies that could be used by nurses working with this population. First, an epidemiological study will be conducted in vaccination clinics: 288 4-5-year-olds will be weighed and measured. Next, semi-structured interviews will be conducted with 20 parents to describe their representation of $\mathrm{HL}$ and their child's weight. Based on the results from these two steps, by means of a focus group nurses will identify possible strategies to the problem. Finally, focus groups of parents, then nurses and finally experts will give their opinions of these strategies in order to find a direction for these strategies. Descriptive and correlational statistical analyses will be done on the quantitative survey data using SPSS. Qualitative data will be analyzed using Huberman and Miles' (2003) approach. NVivo will be used for the analysis and data management.
\end{abstract}

Discussion: The anticipated benefits of this rigorous approach will be to identify and develop potential intervention strategies in partnership with preschoolers' parents and produce a clinical tool reflecting the views of parents and nurses working with preschoolers' parents.

Keywords: Overweight, Childhood, Preschool, Parental opinion, Health promotion, Action research

\section{Introduction}

The focus of this study is the promotion of a healthy lifestyle from an early age to prevent increasing overweight in preschool children. This proposal first outlines the background, the study goals and objectives, and the literature review. The literature concerns overweight in preschool children and associated factors, parents' perception of their child's weight and current efforts to

\footnotetext{
*Correspondence: lucie.lemelin@uqo.ca

${ }^{\dagger}$ Equal contributors

'Nursing Department, UQO, Saint-Jérôme, Canada

Full list of author information is available at the end of the article
}

promote a healthy lifestyle in young children. The proposal then describes the research design and setting, the sampling, data collection and analysis strategies. Finally, ethical considerations and anticipated benefits are discussed.

\section{Background}

Childhood obesity is a public health epidemic; 22 million children under the age of 5 are affected [1]. In Canada $21.5 \%$ of children aged $2-5$ years [2] and $13.5 \%$ of fouryear-olds in Quebec (Canada) are overweight [3]. The prevalence doubled between 1978 and 2005. Though

\section{Biomed Central}


self-reported data suggests a more recent stabilization in prevalence, Lamontagne and Hamel [4] caution against over-confidence in this trend because of the socialdesirability bias of self-reported data. Although many factors are involved, lifestyle is at the heart of the problem. In the first years of life, parents play a leading role in the development of a healthy lifestyle [5-7].

Lifestyle and thus modifiable factors associated with overweight in preschool children include frequent consumption of sweetened beverages [8], high-calorie processed foods [9], dietary restrictions [10,11], hours of sleep [12], physical inactivity, and hours spent in front of a screen [13]. So it is not surprising that prevention efforts focus on adopting a healthy lifestyle, namely a healthy diet and increased physical activity [14].

In 2006 Quebec adopted a six-year action plan to promote healthy lifestyles and prevent weight-related problems in children [6]. Priorities include promoting a healthy diet and physically active lifestyle. The plan is aimed at various authorities, including daycare and early childhood educational services, but no direct action with families is envisaged nor have strategies to promote healthy lifestyles in families been defined. One of the objectives of the Quebec program "Integrated perinatal and early childhood services for families living in vulnerable situations" is to improve family lifestyles. However, this program is aimed at a specific group and not the entire population [15]. The vulnerable target population presents health risks such as substance abuse, alcoholism and violence.

The preschool period is a good time to act. This is confirmed by longitudinal studies on the growth curve. The aim is to delay the adiposity rebound ${ }^{a}$ since if it occurs early (before age 6), the risk of being overweight later increases [16-18]. ${ }^{\text {a }}$ The results of a study by Nader et al. [16] indicate that if a child is overweight at age 5, i.e. has a $\mathrm{BMI}>85^{\text {th }}$ percentile, he/she is five times more likely to be overweight at age 12 . However, normal changes in body form and structure at this age [19], complicate accurate perception of overweight.

Being overweight has serious consequences: children can develop low self-esteem and be socially isolated [20] and have a poor self-image as young as age 5 [21]. They also are at risk of cardiovascular disease, modification of the lipid profile, sleep apnea, hypertension and type 2 diabetes in adulthood [22]. Economically, obesity costs the Canadian health care system about $\$ 4.3$ billion in 2000-2001 [23].

Despite the consequences of overweight for the child and for society, few parents view their children as overweight $[24,25]$. Few studies have attempted to do an indepth analysis of the reasons for this erroneous view. The representation of childhood overweight and a healthy lifestyle from the parents' point of view, which has received little or no attention to date, could shed light on the reasons for this misperception. Representation consists of beliefs, attitudes, opinions and knowledge about something [26]. Thus it guides the actions of parents and, in this case, behaviours and lifestyles of children.

In Quebec, nurses regularly see children for vaccinations and other services prior to school entry. These contacts present an opportunity to take action in early childhood. But how can nurses support families in adopting healthy habits? To answer this question, we have designed an action research study involving nurses, parents and experts to identify the views of parents and healthcare professionals regarding the promotion of a healthy lifestyle and to develop clinical tools based on new knowledge derived from the description of the parents' representation.

\section{Relevance of the study}

Currently, in the absence of systematic interventions to promote a healthy lifestyle among parents of preschoolers, it is imperative for nurses to understand the parents' point of view in order to provide them with adequate support. The relevance of this study is that it is important to understand the representation of overweight and healthy lifestyles among preschoolers' parents in order to intervene early and meet their needs effectively. This study is justified because these elements must be clarified in order to tailor interventions to promote healthy lifestyles accordingly. Moreover, the development of healthy lifestyles, healthy development in childhood and the health services available are three determinants of health that need to be targeted to prevent overweight in Canada [7]. Developing a clinical tool for public health nurses will facilitate the provision of evidence-based services and is likely to improve the quality of services. Professional practices will be relevant and based on the viewpoint of parents as key players in adopting healthy lifestyles for their children and helping to address overweight, which is a serious public health problem.

\section{Study goals and objectives}

The aim of the study is to identify, with nurses working with families, possible solutions to promote healthy lifestyles among parents of preschool children after exploring parents' representation of overweight and healthy lifestyles in preschoolers. The specific objectives are to: 1) document the current situation (estimate the prevalence of overweight and describe the associated factors) in preschool children attending a vaccination clinic in a region of Quebec, Canada, 2) describe the representation of overweight and health lifestyles according to parents of preschoolers, 3) explore the viewpoint of nurses 
working with young families concerning possible interventions that could be used to develop a clinical tool to promote healthy lifestyles, and 4) achieve a direction on which strategies to promote and which of the proposed strategies to prioritize.

\section{Literature review}

We present current knowledge concerning the issue of overweight in preschool children, specifically: the etiology of overweight and known associated factors, the importance of acting in early childhood and the parents' perception and representation of this issue. Finally, current health promotion efforts to address overweight in children and the conceptual framework used for this research will be presented and justified.

\section{Etiology of overweight and associated factors}

For the purpose of this study, the term 'overweight' includes both excess weight and obesity, which are mea-

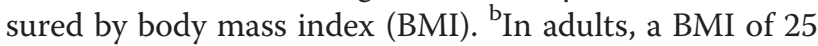
to 30 indicates overweight, and over 30 , obesity. In children, three BMI cut-points have been proposed by CDC [27], WHO [28] and IOTF [29], respectively. For the CDC, BMI percentiles classify children as overweight $\left(\mathrm{BMI}>85^{\mathrm{th}}\right)$ and obese $\left(\mathrm{BMI} \geq 95^{\mathrm{th}}\right)$. The WHO uses the z-score of BMI-for-age, with children classified as overweight with a BMI between one and two standard deviations (SD) above the mean and as obese with more than two SD above the mean. This translates to overweight as a BMI $>84^{\text {th }}$ and obese as a BMI $>97.7^{\text {th }}$ percentile. To obtain accurate baseline values, the IOTF defined BMI thresholds that take the child's age and sex into account. For IOTF, a child is considered overweight with a BMI $\geq 91$ th and obese with a BMI $\geq 99^{\text {th }}$ percentile for their age-sex referent. The IOTF criteria constitute an international definition of childhood overweight. The reference values are based on data obtained from six different countries. This definition makes it possible to assess the prevalence of overweight and compare it to other studies because it was developed specifically for international comparaison.

Etiologically, overweight occurs when calorie intakethe amount of energy consumed-exceeds caloric expenditure over a long period of time [30,31]. In North America, restaurant portions for children are $24 \%$ larger than necessary [32], convenience food is high in calories [33] and children consume large amounts of sweetened beverages $[8,34]$. The availability of ready-to-eat food in grocery stores and 'fast food' restaurants contribute to changes in families' eating habits [9]. As for energy expenditure, a sedentary lifestyle, time spent in front of a screen $[13,35,36]$ and the presence of a screen (television or monitor) in the child's bedroom all contribute to weight gain [37].
Other parental factors increase the risk of the child being overweight: a) one or both parents being overweight leads to a $50 \%$ or $70 \%$ higher risk respectively [38]; b) low family income makes it difficult to afford healthy food [39]; c) mother not having completed high school [13]; and d) dietary restrictions (forbidden fruit is always more attractive) $[10,11]$. Also, the risk is higher in preschool children who sleep less than 10 hours per night [12].

\section{Acting early in childhood to promote healthy lifestyles}

As mentioned earlier, if the adiposity rebound occurs before age 6 , the risk of later obesity is high compared to an adiposity rebound occurring after age 6 [16-18]. Because of this, it is important to act early. In a study by Canning, Courage and Frizzell [40] involving 4161 children from three to five years old, the results show that it is important to take action as young as age 3 since one in four children is overweight by the age of $3 \frac{1}{2}$. Knowing that young children can be influenced by the food environment of the adults around them, this factor must be considered when considering the best time to intervene [41]. When the child is young, the family is the place to develop healthy behaviors [5], hence the importance of supporting parents in adopting healthy lifestyles when their children are very young.

\section{Parents' perception of their child's weight}

Quantitative studies on perception identified in the literature aim to determine if parents are aware of their child's weight. Six studies, published in English or French, concerning preschool children were published between 2003 and 2010 are presented. Table 1 summarizes the main findings of these studies.

Despite differences in the children's age, target populations and slight variations in how weight perceptions were measured, all of the studies found that the parents did not view their overweight child as having excess weight. The study by Maynard, Galuska, Blanck and Serdula [43] and Manios et al. [42] are the only two with a representative sample of the population nationally. The other studies shown in Table 1 looked at samples from a program for underprivileged children in which overweight is more pronounced. Only four of the five studies concerned preschoolers only.

\section{Parents' representation of overweight and lifestyle}

Parents' representation of overweight could partly explain why they do not see it, which could in turn guide efforts to promote healthy lifestyles. Many authors have studied the concept of representation [46-52]. Representation is a mental activity by which a group reconstitutes the reality before it and attributes a meaning to it [46]. Abric [26] proposes an operational definition that is the 
Table 1 Parental perception of child's weight

\begin{tabular}{|c|c|c|c|}
\hline Authors/Country & Design/Aim & n/yrs & Results \\
\hline Bossink-Tuna et al. (2009) [24] & \multirow[t]{2}{*}{ Cross-sectional surveys } & 635 & \multirow{2}{*}{$\begin{array}{l}87 \% \text { of parents of overweight children disagreed that their child } \\
\text { was overweight }\end{array}$} \\
\hline Netherlands & & $2-4$ & \\
\hline Carnell et al. (2005) & \multirow{10}{*}{$\begin{array}{l}\text { Determine parents' perceptions } \\
\text { of their child's weight } \\
\text { compared to measured weight }\end{array}$} & 564 & \multirow{2}{*}{$\begin{array}{l}98.1 \% \text { of parents of overweight children and } 82.9 \% \text { of parents } \\
\text { of obese children did not perceive him/her as overweight }\end{array}$} \\
\hline United Kingdom [25] & & $3-5$ & \\
\hline Manios et al. (2009) & & 2287 & \multirow{2}{*}{$\begin{array}{l}55.4 \% \text { of parents of overweight children and } 88.0 \% \text { of } \\
\text { at-risk-of-overweight children perceived him/her as normal weight }\end{array}$} \\
\hline Greece [42] & & $\overline{2-5}$ & \\
\hline Maynard et al. (2003) & & 5500 & \multirow{2}{*}{$\begin{array}{l}32.1 \% \text { of mothers of overweight children reported that he/she } \\
\text { was about the right weight }\end{array}$} \\
\hline United States [43] & & $2-11$ & \\
\hline Vuorela et al. (2010) & & 310 & \multirow{2}{*}{$\begin{array}{l}72.7 \% \text { of parents of overweight boys and } 93.8 \% \text { of overweight } \\
\text { girls classified them as normal weight }\end{array}$} \\
\hline Finland [44] & & 5 & \\
\hline Wald et al. (2007) & & 612 & \multirow{2}{*}{$\begin{array}{l}82.5 \% \text { of the parent of } 3-5 \text { years-old children their overweight } \\
\text { children did not identify their child as overweight }\end{array}$} \\
\hline United States [45] & & $\overline{3-12}$ & \\
\hline
\end{tabular}

sum of opinions, attitudes, beliefs and knowledge about a specific situation. Also, the representation guides behavior and is a precursor to taking action [46].

There are no studies on parents' representation of overweight and healthy lifestyles in preschool children; there are a few studies on the representation of food. However, Pelicand and Doumont [53] identified 50 exclusively or partly qualitative studies on the perception of the child's weight to shed some light, from interview transcripts, on representation. Among the factors identified was a belief that obesity is less important than other health risks like passive smoking [54] and that overweight is a medical problem when the child cannot participate in physical activities with peers [55]. Moreover, according to some parents, overweight children are "big and strong" and a "big baby" is a sign of good health and good parenting [43]. The younger the child, the more overweight is made light of by mothers, believing that the child will inevitably grow and overweight will disappear [55]. Other parents think that weight and height are preprogrammed and thus impossible to change [55]. These aspects are interesting but cannot be used to comprehensively identify parents' representation of overweight and healthy lifestyles in children. A description of opinions, attitudes, beliefs and knowledge, i.e. a comprehensive representation of overweight and healthy lifestyles, could help to understand why parents see little or no overweight when it is present in their child. This knowledge could also help guide current efforts to promote healthy lifestyles in parents of young children.

\section{Interventions to promote healthy lifestyles and prevent overweight in children}

The aim of the meta-analysis by Flynn et al. [56] was to identify programs advocating obesity prevention best practices. A total of 147 programs were found and 26\% were considered feasible, useful and effective. The best practices identified were those targeting the school population and including a BMI assessment, identification of chronic disease risk factors and participants' involvement in physical activities. One of the findings was a lack of programs for children up to age 5 and widelyvarying practices. A limitation of this meta-analysis was the broad inclusion criteria for programs making them difficult to compare in terms of effectiveness because of their different designs and measures. Summerbell et al. [57] also did a meta-analysis of 22 randomized studies to measure the impact of interventions addressing diet or physical activity or a combination of the two in children. The results show that the studies on interventions are rarely conclusive and that it is difficult to compare results because of differing designs, interventions and measures. Of the studies identified by these two metaanalyses, two specifically targeted preschool children and give an insight into possible overweight prevention interventions.

The first study by Harvey, Berino and Rouke [58] was a randomized clinical trial with 43 mothers of two-yearolds aimed at determining the effectiveness of helping immigrant parents to reduce obesity. In-home meetings provided education on diet and physical activity. The focus for the intervention was to improve parenting skills to develop appropriate eating and exercise behaviors to prevent obesity. The results showed a 0.27 decline in the mothers' BMI and a commitment to monitor their child's food intake. In this study, the randomization of the sample was not specified, only mothers with a BMI $\geq 25$ were included and the majority of the mothers were Native American, which limits the generalizability of the results. In the second study by Dennison, Russo, Burdick and Jenkins [59] involving 83 mother/child dyads, the aim was to develop and evaluate an intervention to reduce television viewing time. The intervention programme consisted of 39 weeks of 1- 
hour sessions, including 32 sessions on healthy eating and seven sessions to encourage reduction of TV viewing for both parents and children. The stratified randomized clinical trial showed that the children reduced their television viewing time but actual times were not measured; parental estimates of the child's sedentary activity in previous week were lower than before the intervention. Knowing that the time spent in front of a screen reduces the time spent on physical activities, the results seem interesting. However, the impact on weight was not presented. In summary, the results of intervention studies are inconclusive and few of them looked at preschool children.

Despite none or minimal impact on weight, these studies demonstrate short and medium-term changes in health habits, notably in better food choices, increased physical activity and less sedentary behavior. Identifying appropriate strategies and interventions for successful health promotion requires a precise definition of the problem, identification of the target group (parents and professionals), and the influencing factors (home environment) [60].

Thus, the evidence of interventions to reduce childhood overweight is inconclusive. With this study, we hope to establish a foundation for designing a future intervention based on the ecologic model, that will also take into account the evidences actually published. To that end, we are taking into consideration the points of view of the major determinant of the child environment, the parent. Understanding what influences the parent's representation of overweight will help design interventions adapted to the stages of change. We also target clinicians who come into predictable and regular encounters with the parent during the preschool period. Exploring the viewpoint and engaging clinicians and local decision-makers will outline the scope of influence and action they can exert, especially in targeting actions or communication that take into account parental representation of overweight. Finally, we will consider experts opinion on the subject to encompass a broader scope of potential strategies to better support parents in promoting healthy lifestyles for their children.

\section{Conceptual framework}

In view of the findings regarding parents' misperception of overweight in their preschool children, the fundamental role that parents play in the adoption of children's healthy lifestyles and interventions that primarily target a change in behavior by the adoption of healthy lifestyles, the conceptual framework used for this study is the Transtheoretical Model [61]. This is a model used to change behaviors [62]. According to the Transtheoretical Model, behavioral change takes place through five stages, allowing us to understand when changes in thoughts, intentions, attitudes or behaviors occur [63]. The stages in the model are outlined in Table 2. This model has also been used in interventions with families. For example, Weiss [64] based the therapeutic education of asthmatic children and their families on this model.

From the literature review, it appears that interventions promoting healthy lifestyles with parents of young children are more likely to reach a population aware of the overweight issue (stages 3 and 4) because they see a problem that concerns them. The interventions, aimed at adopting a healthy diet or doing physical activity, correspond to changes in behavior that require first an intention to act with regard to the problem perceived as important and representing a definite risk for the child. If parents do not view their child as being overweight, why would they intend to change their lifestyle? Thus there is an incompatibility between the stage many parents are at and the stage targeted by interventions. Given that most parents are at stages 1 and 2 with respect to their children's overweight, it is vital to understand parents' representation of overweight and healthy lifestyles in preschool children in order to develop strategies to promote healthy lifestyles and raise awareness (stages 1 and 2) by clarifying parents' beliefs, attitudes, opinions and knowledge.

Nonetheless, promotion of health lifestyles much take into account the environment in which parents and their children adopt health behaviours. Thus, the ecologic model of Bronfenbrenner (1979) will be used as the conceptual background in order to consider the different

Table 2 Stages of the transtheoretical model

\begin{tabular}{lll}
\hline $\mathbf{1}$ & $\begin{array}{l}\text { Description } \\
\text { the problem, has no interest in change }\end{array}$ & Interventions \\
\hline $\mathbf{2}$ & $\begin{array}{l}\text { Recognizes the problem, gathers } \\
\text { information, does not take action }\end{array}$ & Rvaluate self-confidence, discuss the pros and cons of the behavior to be changed \\
\hline $\mathbf{3}$ & Decides to act, plans the change & $\begin{array}{l}\text { Discuss the pros and cons, help and guide the individual in his/her approach, remind of } \\
\text { past successes }\end{array}$ \\
\hline $\mathbf{4}$ & Applies new behavioral strategies & Discuss the pros and cons of the change and provide positive reinforcement \\
\hline $\mathbf{6}$ & Incorporates changes in own lifestyle & Positively reinforce desired behaviors, remind of successes and recognize danger signs \\
\hline
\end{tabular}


elements to be considered in the design of interventions to promote adoption of healthy behaviours. So, the Transtheoretical Model will allow health professionals to adapt interventions to the stage of change and of motivation of the parent, integrating both parents' representation of child overweight and knowledge coming from the literature. The ecological model will allow intervention on obesogenic environment which parents sometimes inadvertently create.

\section{Method}

\section{Research design}

The action research design is a systematic and participatory investigation approach based on the pragmaticinterpretative paradigm $[65,66]$. This design, through cycles or loops, helps to understand problems and formulate actions directed towards problem-solving [67]. The ultimate aim, objectives and orientations are based on discussion and negotiation with the participants. The researcher takes a participatory attitude to achieve real cooperation [67]. The type of action research proposed by Stringer and Genat [67] targets reflexive professional practice aimed at empowering professional groups to defend clients' interests. Thus the focus is on the professional who defines the problem based on his/her own practice. The change targets professional practice and the solutions emerging from the professionals and target population. In this study, nurses working with preschool children try to determine possible interventions to promote healthy lifestyles among parents of preschool children to prevent increasing overweight.

In the present action research four cycles (loops) are proposed. Each loop meets a study objective and is composed of a reflection phase and an action phase. Each loop will be described in terms of the methodological approach, sampling strategy and data collection and analysis methods. First, however, the research setting is described.

\section{Research setting}

For this study the research team consists of two professors and a doctoral student. Throughout the study, an advisory committee of stakeholders in the region where the study is conducted will contribute at various steps in the study. The committee members will monitor the study and participate in the thinking regarding its objectives. They come from the local health and social services agency, network of daycare centres, CSSS, the municipality and parents.

The intervention area is a region in the province of Quebec, Canada. The population of this region was 43,953 in 2008 and included 6006 children up to 14 years of age [68]. The preschool vaccination clinics reach many families in both urban and rural areas.

\section{Awareness of overweight in preschoolers (loop 1)}

As the starting point for the study, the nurses participating in the study want to know more about overweight in their preschool population. The first step will be to conduct a prevalence survey. This will provide the participating nurses and researchers with a profile of the population served to initiate thinking and discussions of the study issue. Descriptive quantitative data will be collected to document the situation by estimating the prevalence of overweight and describe the known risk factors.

\section{Sample (loop 1)}

The study population will be composed of preschoolers who came to vaccination clinics in 2010. The probabilistic sample will comprise 288 consecutive children, for a $95 \%$ confidence level, a 5\% margin of error and a prevalence that could go up to $25 \%$. The $25 \%$ estimate will provide sufficient statistical power. The sample will be created with the consent of the nurses working in the vaccination clinics.

\section{Data collection (loop 1)}

The variable of interest is childhood overweight (BMI) for which the reference values used will be those developed by Cole et al. [29]. The following variables will be described: the child's age, sex, health problems and medications, the family's postal code (socioeconomic level), the parents' education, and the height and weight (selfdeclared) of the parent bringing the child to the vaccination clinic. Data will be collected with a selfadministered questionnaire developed specifically for the study, which will be cognitively tested with ten parents to ensure the clarity of the questions, visual presentation and time required to complete it. It will be anonymous and a consent form will be given and explained to parents prior to the questionnaire. At the vaccination clinic, the student-researcher will measure the child's height and weight and enter this information on the questionnaire, together with the age and sex. She will then give the questionnaire to the parent. At this point, the parent can decide to complete the questionnaire or not. It is expected to take five minutes. A subsection of the questionnaire will invite the parent to voluntarily provide contact information to participate in an interview or focus group in the later loops in the study. After completion, the questionnaire will be left at a specified place.

\section{Description of parents' representation of overweight and lifestyle (loop 2)}

For loops 2, 3 and 4, an inductive qualitative approach will be used to explore the views of parents, nurses, and experts. The qualitative approach has the advantage of describing in depth important social aspects relating to a 
situation [69]. This approach will also encourage nurses to participate in the search for intervention strategies to promote healthy lifestyles adapted to both the parents' needs and the situation at the clinic. Throughout these loops, the researcher will keep a log documenting the views of the student researcher and the effect of the site on the student.

Loop 2 will start with presenting to the participant nurses the results obtained in loop 1 , namely the population profile. Then discussions will take place between the nurses and student researcher concerning the information required from parents to continue the reflection. The objective of loop 2 is to describe the representation of parents of preschool children of overweight and healthy lifestyles of children in this age group. The representation will be constructed from parents' beliefs, opinions, attitudes, knowledge and perceptions about their preschool child's weight and life habits. This information will give the nurses and researchers a better understanding of the parents' views and help them reflect on possible strategies to facilitate the promotion of healthy lifestyles with parents of preschool children.

\section{Sample (loop 2)}

The study population is composed of parents of fourand five-year-olds who come to the preschool vaccination clinic. The purposive sample will be created on the basis of the BMI calculated from Cole et al.'s [29]reference values. The sample will include 20 parents (key informants) of a normal weight or overweight child who, on the questionnaire completed in the previous step, agreed to be contacted for the next step in the study. The inclusion criteria will be having completed the questionnaire in loop 1 and understanding French. Parents of children with health problems (e.g. Trisomy 21) or taking medication that can affect weight (e.g. corticosteroids) will be excluded from this part of the study. Taking into account factors associated with overweight identified in loop 1 will ensure maximum variability when selecting the loop 2 participants.

\section{Data collection (loop 2)}

Data will be collected in two semi-structured interviews, conducted with the help of an evolving guide. The interviews will explore the concept of the representation of overweight and lifestyles from the parents' viewpoint. The first will last about 60 minutes and the second 30 minutes. For the interviews, the researchers have developed an interview guide based on the literature on representation, overweight and healthy lifestyles. The guide will be added to, improved and modified following the discussions with the advisory committee and nurses during the presentation of the results from loop 1 and in the light of findings from the literature. A few examples of questions in the guide are as follows: What words or images come to mind when you think about the lifestyles and weight of four- and five-year-old children? Talk to me about children's weight and lifestyles. Fourand five-year-old children can be overweight-What do you think about that? What challenges do parents face concerning lifestyles?

The procedure will consist of a first telephone call to the parents to explain the objective of this loop, answer their questions, obtain their consent and make an appointment. The consent form will be read and signed before the first interview. The second in-depth interview will take place three to five weeks after the first and serves to specify the researchers' understanding of the first interview and to explore in-depth some additional issues. A summary of the previous interview will be sent to the parent before the second interview. All interviews will be recorded and transcribed. Data will be considered saturated when there is data redundancy and no new information is identified $[69,70]$.

\section{Search for possible solutions to promote healthy lifestyles (loop 3)}

The objective of this loop is to explore the views of nurses working with young families concerning possible strategies to develop a clinical tool to promote healthy lifestyles based on the results from the previous loop. The search for interventions will be affected by the results obtained concerning the parents' views on the representation of overweight and healthy lifestyles, the conceptual framework (transtheoretical model) and relevant literature.

\section{Sample (loop 3)}

The sample will consist of 9 participating nurses working with the target population. As participants, the nurses and researchers will work together to identify possible interventions adapted to the population's needs.

\section{Data collection (loop 3)}

The data will be collected through a focus group discussion, using a guide designed for this purpose. The aim of the questions will be to document the nurses' views of the results from loop 2. First, a meeting will be held with the nurses to present the objective of this third loop and give them a consent form. They will be given a week to complete and return the consent form by mail to the student researcher. The focus group is an approach that has a flexible structure, is quick and inexpensive and is aimed at developing a consensus. The focus group will be held with a facilitator and an observer. The facilitator will ask questions, encourage participation [71] and manage the order of speaking and dominant members [72]. The observer will take notes, verify the content 
discussed and clarify certain elements. The meeting will last 2 hours and the discussion will be recorded and transcribed.

\section{Search for direction concerning the proposed strategies (loop 4)}

The objective of this last loop is to guide the choice of potential solutions stemming from the work done in the previous loop with the nurses. The solutions will be discussed with the nurses themselves, parents and experts.

\section{Sample (loop 4)}

Three purposive groups will be formed. The first group will consist of six parents of preschool children, the second group will involve nine participating nurses working with the target population, and the third will consist of six advisors who have agreed to act as experts (a pediatrician, nutritionist, nurse, community health worker, endocrinologist, other researchers)

\section{Data collection (loop 4)}

This loop involves three phases. First, a focus group discussion with seven parents will obtain their views regarding the proposed strategies. Second, a focus group discussion with ten nurses will gather obtain their views regarding the proposed solutions. Both focus groups will be held with a facilitator and an observer. They will last 60 to 90 minutes and the discussions will be recorded and transcribed. Informed consent will be obtained from the participants (parents and nurses) before the meetings. From both groups we will identify strategies, privileging those that emerge independently from both groups and those that the nurses are confident they can implement. Third, a postal questionnaire including open-ended questions will be sent to the seven experts asking for their opinion regarding the possible strategies suggested by the parents, nurses and researchers. The experts will be requested to rank the suggested strategies by expected impact and relevance. This loop with identify a small number of strategies that will be form the starting point of a subsequent intervention study.

\section{Data analysis (loops 1, 2, 3 and 4)}

The statistical analyses of the data from loop 1 will provide a prevalence estimate, i.e., percentage of children of normal and overweight (excess weight and obese). SPSS software will be used.

For qualitative data, recorded sessions will be transcribed and analyzed using Huberman \& Miles [73] method. For loop 2, parental representation, the data will be condensed using a preliminary analysis grid with various categories, based on predetermined categories that emerged from the literature review, to which emerging categories will be added. The data will be regrouped according to common characteristics of elements in the content and the four representation attributes (beliefs, attitudes, opinions and knowledge). Two researchers will code the data, which will be presented using matrices based on conceptual groupings. The analysis process will start by listening to the interviews, then coding the content of the interviews. The analysis grid will be refined throughout the process because the data from loop 2 will be analyzed concurrently with the interviews. Finally after reviewing the categories and coding and discussions with the advisory committee, the determination of a final categorization can be completed. The same process will be used for focus group discussions in loops 3 and 4. During the analysis process, there will be regular discussions with the research team. Then, based on the data analyzed, literature review and views of the experts, strategies to promote healthy lifestyles (solutions considered) can be proposed. The qualitative data will be managed with NVivo software.

\section{Rigor of the research process}

Throughout the action research, rigorous methodological standards will be met. Credibility, which is the correspondence between the participants' constructions and the reconstructions formulated, will be achieved by an iterative process between researchers, parents and nurses. In addition, triangulation of data sources (parents, professionals, experts and literature) and triangulation of researchers will ensure better correspondence between the results and field data. Data will be coanalyzed including a reflexive stance and there will be frequent team discussions. Finally, recording and transcribing the individual interviews and focus groups will make it possible to confirm the findings by independent analysis. The context, participants' characteristics and results will be detailed in depth, which facilitates transferability. To ensure reliability, i.e., taking into account the evolution of the phenomenon, a lot of time will be spent in the field and discussions with the advisory committee will be held throughout the study [69]. A logbook will be kept and an observer will attend the focus groups in order to keep track of the contextual aspects.

\section{Ethical considerations}

The study was approved by the research ethics boards of the Centre hospitalier universitaire de Sherbrooke (CHUS) and Université de Sherbrooke and the Centre de Santé et des Services sociaux (CSSS) Rivière-duNord/Nord de Mirabel. Parents and nurses will be asked to sign free and informed consent forms before each data collection. Parents and nurses will be able to withdraw from the study at any time without prejudice. Anonymity will be preserved for those parents who do not wish to be contacted again, and no nominative 
information will be retained. Confidentiality will be safeguarded in the usual way, such as by keeping the data under lock and key for 5 years, with access restricted to the research team.

The main ethical issues in this study relate to stigmatization of the child and culpability of the parent. Preschool children are a vulnerable group. It will not be possible to identify them (the questionnaire in loop 1 does not ask for children's names), which reduces the risk of being stigmatized. Also, to reduce the risk of stigmatization, we will ask the parents for permission to weigh and measure all the children, regardless of their apparent weight, for the study. The risk of stigmatization arises later in the lives of children who are overweight for a significant period of time. The parents of children of both normal and overweight will be interviewed, which will minimize the culpability aspect potentially related to the subject of the study. Precautions will be taken when formulating the questions for the interview guide used in loop 2. In addition, psychological support for the family will be available if required at the local health centre (a partner in the study). Particular attention will be paid throughout the study so that parents feel competent in their role.

\section{Anticipated benefits}

The results will give an appreciation of the magnitude of the weight problem in a specific region of Québec and the opportunity to evaluate weight in a vaccination clinic, will describe parents' representation of overweight and healthy lifestyles in preschoolers, will initiate reflection for the professionals involved and will put in place actions designed to equip parents and families of preschool children in order to prevent and reduce the risks of being overweight. Identification by the professionals of strategies to promote healthy lifestyles in families with preschoolers will be derived from evidence-based data from parents and the literature. The professionals involved in this action research will become more aware of the phenomenon and more expect to benefit from a transfer of knowledge. In addition, the nurses will have resources that will help them intervene and make maximum use of meetings with parents of preschool children to address this health problem. The proposed solutions will foster the integration of new interventions into current practice and open the door to future research on these interventions.

\section{Conclusion}

This action research will create partnerships between professionals, parents and experts; these, in turn, are expected to lead to interventions to promote the adoption of healthy lifestyles and prevent overweight in young children. The specific nature of the proposed interventions will be co-determined with the different stakeholders. Specifically, depending on the orientations that emerge from the current research, we will use participatory methods to combine input from our different stakeholders with the evidentiary base on interventions to design an intervention. Again drawing on participatory and qualitative methods, we will test the acceptability and feasibility of the proposed intervention to broader sample of parents and health professionals. We will follow with a pilot study, then a full experimental design to evaluate its efficacy. In addition, the partner and members of the advisory committee for this study will work closely with the researchers to suggest innovative ways to disseminate the results and to integrate results into practice.

\section{Endnotes}

${ }^{a}$ The adiposity rebound is the increase in body mass index (BMI) after age 6: the BMI declines until age 6 as height increases faster than weight. At age 6 height and weight increase simultaneously and the curve rebounds.

${ }^{\mathrm{b}} \mathrm{BMI}=$ Weight $(\mathrm{kg}) /$ Height $(\mathrm{m})^{2}$.

\section{Competing interests}

The authors declare that they have no competing interests

\section{Authors' contributions}

The protocol was designed and drafted by Lucie Lemelin in the context of her doctoral studies in Nursing Sciences. Frances Gallaher, as principal supervisor, and Jeannie Haggerty as co-supervisor, advised on design and provided input to various versions of the protocol. All authors read and approved the final manuscript.

\section{Acknowledgements}

This research project is unfunded but Lucie Lemelin received salary and some research support through a doctoral training award by the Quebec Ministry of Education Sport and Leisure, and was granted leave to conduct her doctoral studies by the Department of Nursing Sciences at the Université de Quebec en Outaouais.

\section{Author details}

Nursing Department, UQO, Saint-Jérôme, Canada. ${ }^{2}$ Nursing School, Sherbrooke University, Sherbrooke, Canada. ${ }^{3}$ Epidemiology Department, McGill University, Montreal, Canada.

Received: 8 February 2011 Accepted: 5 July 2012

Published: 1 August 2012

\section{References}

1. World Health Organization (WHO): Global Strategy on Diet, Physical Activity and Health: Obesity and Overweight; 2005. http://www.who.int/ dietphysicalactivity/strategy/eb11344/strategy_english_web.pdf] Accessed July 2012.

2. Shields M: Overweight Canadian children and adolescents. Nutrition: Findings from the Canadian Community Health Survey. Ottawa: Statistics Canada; 2005.

3. Desrosiers $\mathrm{H}$, et al: Enquête de nutrition auprès des enfants québécois de 4 ans. Québec: Institut de la statistique du Québec; 2005.

4. Lamontagne P, Hamel D: Le poids corporel chez les enfants québécois 1978 à 2005: INSPQ; 2009. Accessed http://www.inspq.qc.ca/pdf/publications/ 936_PoidsEnfant1978-2005.pdf.

5. Campbell K, Crawford DA, Ball K: Family food environment and dietary behaviors likely to promote fatness in 5-6 year-old children. Int J Obes 2006, 30(8):1272-1280. 
6. Lachance B, Pageau M, Roy S: Investir pour l'avenir. Québec: Direction des communications du Ministère de la Santé et des Services sociaux; 2006.

7. Health Canada; 2004. http://www.hc-sc.gc.ca/hcs-sss/pubs/renewal-renouv/ 1997-nfoh-fnss-v2/index-eng.php. Accessed July, 2012.

8. Dubois L, Farmer A, Girard M, Peterson K: Regular sugar-sweetened beverage consumption between meals increases risk of overweight among preschool-aged children. J Am Diet Assoc 2007, 107(6):924-934.

9. Gillis $\sqcup$, Bar-Or O: Food away from home, sugar-sweetened drink consumption and juvenile obesity. J Am Coll Nutr 2003, 22(6):539-545.

10. Faith MS, Berkowitz RI, Stallings VA, Kerns J, Storey M, Stunkard AJ: Parental feeding attitudes and styles and child body mass index: prospective analysis of a gene-environment interaction. Pediatrics 2004, 114(4): e429-e436.

11. Faith MS, Scanlon KS, Birch LL, Francis LA, Sherry B: Parent-child feeding strategies and their relationship to child eating and weight status. Obes Res 2004, 12(11):1711-1722

12. Reilly JJ, Armstrong J, Dorosty AR, Emmett PM, Ness A, Rogers I, Steer C, Sherriff A: Early life risk factors for obesity in childhood: cohort study. $\mathrm{Br}$ Med J 2005, 330(7504):1357-1359.

13. Dubois L, Farmer A, Girard M, Peterson K: Social factors and television use during meals and snacks is associated with higher BMI among preschool children. Public Health Nutr 2008, 11(12):1267-1279.

14. Lau D, Douketis J, Morrison K, Hramiak I, Sharma A, Ur E: 2006 Canadian clinical practice guidelines on the management and prevention of obesity in adults and children [Summary]. Can Med Assoc J 2007, 176(8 suppl):SF1-SF14

15. Ministère de la Santé et des Services sociaux (MSSS): Les services intégrés en périnatalité et pour la petite enfance à l'intention des familles vivant en contexte de vulnérabilité [Integrated perinatal and early childhood services for families living in vulnerable situations]. 2004. Accessed http://publications. msss.gouv.qc.ca/acrobat/f/documentation/2004/04-836-02W.pdf.

16. Nader FR, O'Brien M, Houts R, Bradley R, Belsky J, Crosnoe R, Friedman S, Mei Z, Susman EJ: Identifying risk for obesity in early childhood. Pediatrics 2006, 118(3):e594-e601.

17. Gardner DSL, Hosking J, Metcalf BS, Jeffery AN, Voss LD, Wilkin TJ: Contribution of early weight gain to childhood overweight and metabolic health: a longitudinal study (EarlyBird 36). Pediatrics 2009, 123(1):e67-e73.

18. Williams SM, Goulding A: Patterns of growth associated with the timing of adiposity rebound. Obesity 2009, 17(20):335-341.

19. Ball J, Bindler R: Soins infirmiers en pédiatrie ( ${ }^{e}$ édition). Montréal: Éditions du Renouveau Pédagogique inc:; 2010.

20. Fischler C: L'homnivore. Paris: Éditions Odile Jacob; 2001

21. Davison KK, Birch LL: Weight status, parent reaction, and self-concept in five-year-old girls. Pediatrics 2001, 107:46-53.

22. Reilly JJ, Methven E, McDowell ZC, Hacking B, Alexander D, Stewart L, Kelnar CJH: Health consequences of obesity. Arch Dis Child 2003, 88(9):748-752.

23. Katzmarzyk PT, Janssen I: The economic costs associated with physical inactivity and obesity in Canada: an update. Physiol Nutr Metab 2004 29(1):90-115.

24. Bossink-Tuna HN, L'Hoir MP, Beltman M, Boere-Boonekamp MM: Parental perception of weight and weight-related behaviour in 2- to 4-year-old children in the eastern part of the Netherlands. Eur J Pediatr 2009, 168:333-339.

25. Carnell S, Edwards C, Croker H, Boniface D, Wardle J: Parental perceptions of overweight in 3-5 y olds. Int J Obes 2005, 29:353-355.

26. Abric J-C: Pratiques sociales et représentations. Paris: Presses universitaires de France; 1994.

27. Centers for Disease Control and Prevention: CDC Growth Charts. www.cdc. gov/growthcharts. Accessed July, 2012. PDF Accessed http://www.cdc.gov/ growthcharts/2000growthchart-us.pdf

28. WHO Multicentre Growth Reference Study Group: WHO Child Growth Standards based on length/height, weight and age. Acta Paediatr 2006, suppl 450:76-85.

29. Cole TJ, Bellizzi MC, Flegal KM, Dietz WH: Establishing a standard definition for child overweight and obesity worldwide: international survey. Br Med J 2000, 320(6):1-6.

30. Ebbeling CB, Pawlak DB, Ludwig DS: Childhood obesity: public-health crisis, common sense cure. Lancet 2002, 360:473-482.

31. Rennie $K L$, Johnson $L$, Jebb A: Behavioural determinants of obesity. Best Pract Res Clin Endocrinol Metab 2005, 19(3):343-358.
32. Fisher J, Rolls B, Birch L: Children's bite size and intake of an entrée are greater with large portions than with age-appropriate or self-selected portions. Am J Clin Nutr 2003, 77(5):1164-1170.

33. Phillips SM, Bandini LG, Naumova EN, Cyr H, Colclough S, Dietz WH, Must A: Consumption of high-calorie, low-nutrient-dense foods over the adolescent period: relationship to body weight and fatness in a longitudinal setting. Int J Obes 2004, 12:461-472.

34. Melgar-Quiñonez HR, Kaiser LL: Relationship of child-feeding practices to overweight in low-income Mexican-American preschool aged children. J Am Diet Assoc 2004, 104:1110-1119.

35. Dennison B, Erb T, Jenkins P: Television viewing and television in bedroom associated with overweight risk among low-income preschool children. Pediatrics 2002, 109(6):1028-1035.

36. Robinson T: Television viewing and childhood obesity. Pediatr Clin N Am 2001, 48(4):1017-1025.

37. Christakis DA, Ebel BE, Rivara FP, Zimmerman FJ: Television, video, and computer game usage in children under 11 years of age. J Pediatr 2004, 145(5):652-656.

38. Sekine M, Yamagami T, Hamanishi S, Handa K, Saito T, Nanri S, Kawaminami K, Tokui N, Yoshida K, Kagamimori S: Parental obesity, lifestyle factors and obesity in preschool children: results of the Toyama Birth Cohort study. $J$ Epidemiol 2002, 12(1):33-39.

39. Armstrong J, Dorosty AR, Reilly JJ: Coexistence of social inequalities in undernutrition and obesity in preschool children: population based cross sectional study. Arch Dis Child 2003, 88:671-675.

40. Canning P, Courage M, Frizzell L: Overweight and obesity in preschool children in Newfoundland and Labrador. Can Med Assoc J 2004, 171(3):240-242.

41. Addessi E, Galloway AT, Visalberghi E, Birsh LL: Specific social influences on the acceptance of novel foods in 2-5-year-old children. Appetite 2005, 45:264-271.

42. Manios Y, Kondaki K, Kourlaba G, Vasilopoulou E, Grammatikaki E: Maternal perceptions of their child's weight status: the GENESIS study. Public Health Nutr 2008, 12(8):1099-1105.

43. Maynard LM, Galuska DA, Blanck HM, Serdula MK: Maternal perceptions of weight status of children. Pediatrics 2003 111(5):1226-1231.

44. Vuorela N, Saha M-J, Salo M: Parents underestimate their child's overweight. Acta Paedistrica 2010, 99:1374-1379.

45. Wald ER, Ewing LJ, Cluss P, Goldstrohm S, Cipriani L, Colborn DK, Weissfeld $\mathrm{L}$ : Parental perception of children's weight in a paediatric primary care setting. Child Care Health Dev 2007, 33(6):738-743.

46. Abric J-C: Pratiques sociales et représentations. Paris: Presses universitaires de France; 1997.

47. Blanc N: Le concept de représentation en psychologie. Paris: In Press editions; 2006.

48. Doise W: Les représentations sociales: définition d'un concept. Paris: Presses universitaires de France; 1986

49. Jodelet D: Représentation sociale: phénomènes, concept et théories. In Psychologie sociale. 7th edition. Edited by Moscovici S. Paris: Presses universitaires de France; 1988

50. Moliner P: Images et représentations sociales. De la théorie des représentations sociales à l'étude des images sociales. Grenoble: Presses universitaires de Grenoble; 1996

51. Moscovici S: La psychanalyse, son image et son public. Paris: Presses universitaires de France; 1961

52. Roussiau N, Bonardi C: Les représentations sociales. États des lieux et perspectives. Hayen: Mardaga; 2001.

53. Pelicand J, Doumont D: Quelles sont les représentations de l'alimentation et de l'obésité chez les parents et enfants? UCL-RESO Dossier technique 05-36, Université catholique de Louvain:; 2005. Accessed July 2012 http://www. uclouvain.be/cps/ucl/doc/reso/documents/Dos36.pdf.

54. Etelson D, Brand DA, Patrick PA, Shirali A: Childhood obesity: do parents recognize this health risk? Obes Res 2003, 11(11):1362-1368.

55. Jain A, Sherman SN, Chamberlain LA, Carter Y, Powers SW, Whitaker RC: Why don't low-income mothers worry about their preschoolers being overweight? Pediatrics 2001, 17(5):1138-1146.

56. Flynn MA T, McNeil DA, Maloff B, Mutasingwa D, Wu M, Ford C, Tough SC: Reducing obesity and related chronic disease risk in children and youth: a synthesis of evidence with "best practice" recommendations. Obes Rev 2006, 7(suppl.1):7-66. 
57. Summerbell CD, Waters E, Edmunds LD, Kelly S, Brown T, Campbell KJ: Interventions for preventing obesity in children. Cochrane Collab 2005, Issue 2:1-70.

58. Harvey Berino J, Rouke J: Obesity prevention in preschool NativeAmerican children: a pilot study using home visiting. Obes Res 2003, 11:606-611.

59. Dennison BA, Russo TJ, Burdick PA, Jenkins PL: An intervention to reduce television viewing by preschool children. Arch Pediatr Adolesc Med 2004, 158:170-176.

60. Renaud L, Lafontaine G: L'élaboration et la realisation d'intervention écologiques en promotion de la santé. In Promotion de la santé au Canada et au Québec, perspectives critiques. Edited by. Lévis: Les presses del'Université Laval; 2006:25-41.

61. Prochaska JO, Diclemente CC: The transtheoretical approach: crossing traditional boundaries of therapy. Malabar: Krieger Publication; 1994. Homewood, IL: Dorsey.

62. Sharma M, Romas JA: Theoretical foundations of health education and health promotion. Sudbury: Jones and Bartlett Publishers; 2008.

63. Prochaska JO, Redding CA, Evers KE: The transtheoretical model and stages of change. In Health behavior and health education. Edited by. San Francisco: Jossey-Bass; 2008:97-121.

64. Weiss L: Pourquoi l'asthme reste-t-il une maladie sous-traitée? La faute du patient? Arch Pediatr 2007, 14(6):696-698.

65. Anadòn M: Nouvelles dynamiques de recherche en éducation. Québec: Les presses de l'Université Laval; 2001.

66. Savoie-Zajc L: La recherche-action en éducation: ses cadres épistémologiques, sa pertinence, ses limites. In Nouvelles dynamiques de recherche en éducation. Edited by Anadón M. Québec: Presses de l'Université Laval; 2001:15-49.

67. Stringer E, Genat W: Action research in health. Upper Saddle River: Pearson Education; 2004

68. Institut de la Statistique du Québec.; 2008. Accessed http://www.stat.gouv. qc.ca/regions/profils/profill5/societe/demographie/demo_gen/ pop_age15_mrc_an.htm. Accessed July, 2012.

69. Poupart J, Deslauriers J-P, Groulx L-H, Laperrière A, Mayers R, Pires AP: La recherche qualitative: Enjeux épistémologiques et méthodologies. Montréal: Gaëtan Morin Éditeur; 1997.

70. Sandelowski M: Theoritical saturation. In The SAGE Encyclopedia of Qualitative Research Methods. Edited by Given LM. Thousand Oaks: Sage: 2008:875-876.

71. Wilkinson S: Qualitative psychology: a practical guide to research methods. London: Sage; 2003.

72. Reed J, Payton VR: Focus groups: issues of analysis and interpretation. $J$ Adv Nurs 1997, 26(4):765-771.

73. Huberman MB, Miles AM: Analyse des données qualitatives. 2nd edition. Brussels: Editions De Boeck; 2003.

doi:10.1186/1472-6955-11-12

Cite this article as: Lemelin et al: Supporting parents of preschool children in adopting a healthy lifestyle. BMC Nursing 2012 11:12

\section{Submit your next manuscript to BioMed Central and take full advantage of:}

- Convenient online submission

- Thorough peer review

- No space constraints or color figure charges

- Immediate publication on acceptance

- Inclusion in PubMed, CAS, Scopus and Google Scholar

- Research which is freely available for redistribution 